\title{
Metaphor, LANGUAge, AND CUlture
}

\section{(Metáfora, linguagem e cultura)}

Zoltán KÖvecses

(Eötvös Loránd University, Budapest - HUNGARY)

\begin{abstract}
Culture and language are connected in a myriad ways. Proverbs, rules of turn-taking in conversations, pronouns of power and solidarity, background knowledge to the understanding of conversations, politeness, linguistic relativity, the principle of cooperation, metaphor, metonymy, context, semantic change, discourse, ideology, print culture, oral culture, literacy, sociolinguistics, speech acts, and so forth, are just some of the concepts in which we find obvious connections between culture and language. Several disciplines within the language sciences attempt to analyze, describe, and explain the complex interrelations between the two broad areas. (For a brief and clear survey, see Kramsch 1998). Can we approach this vast variety of topics from a more unified perspective than it is traditionally done and currently available? The present paper focus on such possibilities.
\end{abstract}

Key-words: language; culture; metaphor.

Resumo: A cultura e a língua estão conectadas numa miríade de formas. Provérbios, regras de tomada de turnos na conversação, pronomes indicativos de poder e solidariedade, conhecimento prévio para o entendimento de conversas, polidez, relativismo linguístico, o princípio a cooperação, metáforas, metonímias, contexto, mudança semântica, discurso, ideologia, cultura impressa, cultura oral, letramento, sociolinguística, atos de fala, além de outros, são apenas alguns dos conceitos nos quais encontramos conexões óbvias entre cultura e língua. Várias disciplinas das ciências linguísticas tentam analisar, descrever e explicar as interrelações complexas entre estas duas grandes áreas. (Para uma revisão breve e clara, consultar Kramsch 1998). Será que podemos abordar esta vasta variedade de tópicos de uma perspectiva mais unificada do que tem sido tradicionalmente feito e está geralmente disponível? O presente artigo enfoca tais possibilidades.

Palavras-chave: língua; cultura; metáfora.

\section{MeANing MAKING}

I suggest that we can approach the issue of the relationship between culture and language from a more unified perspective if we assume that 
both culture and language are about making meaning, that is, if we make meaning the central element and, indeed, the central issue, in the study of both culture and language. This view of culture comes closest to that proposed by Geertz (1973), who wrote: "Man is an animal suspended in webs of significance he himself has spun. I take culture to be those webs, and the analysis of it to be therefore not an experimental science in search of law but an interpretative one in search of meaning." (Geertz 1973: 5). In this spirit, I suggest that we approach both culture and language as "webs of significance" that people both create and understand. The challenge is to see how they are created and understood-often in multiple and alternative ways.

We have a culture (be it small or large) when a group of people living in a social, historical, and physical environment make sense of their experiences in a more or less unified manner. This means, for example, that they understand what other people say, they identify objects and events in similar ways, they find or do not find behavior appropriate in certain situations, they create objects, texts, and discourses that other members of the group find meaningful, and so forth. In all of these and innumerable other cases, we have meaning making in some form: not only in the sense of producing and understanding language but also in the sense of correctly identifying things, finding behavior acceptable or unacceptable, being able to follow a conversation, being able to generate meaningful objects and behavior for others in the group, and so forth. Meaning making is a cooperative enterprise (linguistic or otherwise) that always takes place in a large set of contexts (ranging from immediate to background) and that occurs with varying degrees of success. People who can successfully participate in this kind of meaning making can be said to belong to the same culture. Spectacular cases of unsuccessful participation in joint meaning making are called "culture shock." (Clearly, though, unsuccessful participation in meaning making can also occur between members of the same culture.)

This kind of meaning-based approach to culture can be found in Lakoffs work on American politics (Lakoff 1996), Turner's (2001) investigations into the cognitive dimensions of social science, and Kövecses's (2005) study of metaphorical aspects of everyday culture. Palmer makes such a meaning-based approach the cornerstone of what he calls "cultural linguistics" and applies it to three central areas of anthropological linguistics: Boasian linguistics, ethnosemantics, and the ethnography of speaking (Palmer 1996: 4-5). 
What is required for meaning making? The main meaning making organ is the brain/mind. The brain (and the nervous system) is the organ that performs the many cognitive operations that are needed for making sense of experience and that include categorization, figure-ground alignment, framing knowledge, metaphorical understanding, and several others. Cognitive linguists and cognitive scientists in general are in the business of describing these operations. Cognitive linguists believe that the same cognitive operations that human beings use for making sense of experience in general are used for making sense of language. On this view, language is structured by the same principles of operation as other modalities of the mind (see, for example, Kövecses 2006). The brain and the cognitive operations used are universal. All human beings share the same kind of brain and the same kind of cognitive operations. However, these cognitive operations are not put to use in a universally similar manner, that is, there can be differences in which cognitive operations are used to make sense of some experience in preference to another and there can be differences in the degree to which particular operations are utilized in cultures. This leads to what is called "alternative construal" in cognitive linguistics (see Langacker 1987). Moreover, the minds that evolve "on brains" in particular cultures are shaped by the various contexts (historical, physical, discourse, etc.) that in part constitute cultures (Kövecses 2005). This leads to alternative conceptual systems.

Many of our most elementary experiences are universal. Being in a container, walking along a path, resisting some physical force, being in the dark, and so forth, are universal experiences that lead to image schemas of various kinds (Johnson 1987, Lakoff 1987). The resulting image schemas ("container," "source-path-goal," "force," etc.) provide meaning for much of our experience either directly or indirectly in the form of conceptual metaphors. Conceptual metaphors may also receive their motivation from certain correlations in experience, when, for instance, people see correlations between two events (such as adding to the content of a container and the level of the substance rising), leading to the metaphor MORE IS UP (see Lakoff and Johnson 1980). When meaning making is based on such elementary human experiences, the result may be (near-)universal meaning (content)-though under a particular interpretation (construal), that is, conceived of "in a certain manner," to use Hoyt Alverson's phrase (Alverson 1991: 97). 
Language, on this view, consists of a set of linguistic signs, that is, pairings of form and meaning (which can range from simple morphemes to complex syntactic constructions). Learning a language means the learning of such linguistic signs. Thus, language can be regarded as a repository of meanings stored in the form of linguistic signs shared by members of a culture. This lends language a historical role in stabilizing and preserving a culture. This function becomes especially important in the case of endangered languages and it often explains why minorities insist on their language rights.

Members of a culture interact with each other for particular purposes. To achieve their goals, they produce particular discourses. Such discourses are assemblies of meanings that relate to particular subject matters. When such discourses provide a conceptual framework within which significant subject matters are discussed in a culture and when they function as latent norms of conduct, the discourses can be regarded as ideologies (see, e.g., Charteris-Black 2004; Musolff 2004, Goatly 2007). Discourse in this sense is another source of making meaning in cultures. A large part of socialization involves the learning of how to make meaning in a culture.

\section{THREE EXAMPLES OF MEANING MAKING}

As the first example, consider how people make sense of the spatial orientation of objects around them. What we find in language after language is that speakers conceptualize the spatial orientation of objects relative to their own bodies (Levinson 1996). This means that they operate with such orientations as "right" and "left" or "in front of" and "behind." Both pairs of concepts make use of the human body in order to locate things in space. Thus, we can say that the window is on my left and that the church is in front of us. If we did not conceptualize the human body as having right and left sides and if we did not have a forward(-backward) orientation aligned with the direction of vision, such sentences would not make too much sense. But in our effort to understand the world, we do rely on such conceptualization. This is called an "ego-centered," or relativistic, spatial orientation system.

Since so many of the world's languages have this system and because the system is so well motivated in our conception of the human body, we 
would think that the ego-centered system is an absolute universal and that no culture can do without it. However, as Stephen Levinson (1996) points out, this is just a myth. The native Australian language of Guugu Yimithirr has a radically different system (Levinson 1996: 180):

Take, for example, the case of the Guugu Yimithirr speakers of N. Queensland, who utilize a system of spatial conception and description which is fundamentally different from that of English-speakers. Instead of concepts of relativistic space, wherein one object is located by reference to demarcated to regions projected out from another reference object (ego, or some landmark) according to its orientation, Guugu Yimithirr speakers use a system of absolute orientation (similar to cardinal directions) which fixes absolute angles regardless of the orientation of the reference object. Instead of notions like 'in front of,' 'behind,' 'to the left of,' 'opposite,' etc., which concepts are uncoded in the language, Guugu Yimithirr speakers must specify locations as (in rough English gloss) 'to the North of,' 'to the South of,' 'to the East of,' etc. The system is used at every level of scale, from millimeters to miles, for there is (effectively) no other system available in the language; there is simply no analogue of the Indo-European prepositional concepts.

The Guugu Yimithirr must carry a mental map in their head of everything surrounding them, with the map aligned for the four quadrants. With the help of such a mental map, they can identify the location of any object with a high degree of precision, far exceeding the ability of speakers of languages which have a relativist system of spatial reckoning.

The second example deals with the cognitive process of categorization. We can suggest that there is a close connection between the nature of our categories and many important cultural and social issues. The classical view of categories is based on the idea of essential features. In order to have a conceptual category, the members of the category must share certain essential features. In the new rival view, categories are defined not in terms of necessary and sufficient conditions (i.e., essential features), but with respect to prototypes and various family resemblance relations to these prototypes.

How do we make sense of social debates? The emergence, existence, and often the resolution of cultural and social issues may hinge on how we think about the nature of our categories. To see how this is possible, let us consider the concept of art. The discussion of the structure of the concept of art can shed light on why art has been a debated category probably ever since its inception and particularly in the past two centuries. Kövecses 
(2006) examines some of the history of the category of art in the past two hundred years on the basis of the Encyclopedia Britannica (2003). What he finds in this history is that the category undergoes constant redefinition in the $19^{\text {th }}$ and $20^{\text {th }}$ centuries. Different and rival conceptions of art challenge the "traditional" view-that is, the most prevalent "conservative" view. Impressionism, cubism, surrealism, pop art, and the like, are reactions to the traditional view and to each other. But what is the traditional view of art?

The traditional conception of art can be arrived at by examining those features of art that are challenged, negated, or successfully canceled by the various movements of art. For example, most people believe that a work of art represents objective reality. This feature of art is canceled by the art movements of impressionism, expressionism, and surrealism. Another feature of art that most people take to be definitional is that a work of art is representational, that is, it consists of natural figures and forms. This feature is effectively canceled by symbolism, cubism, and abstract art. Finally, most believe that a work of art is a physical object. This feature is canceled by conceptual art.

As can be seen, even those features of art that many would take to be definitional for all forms of art (such as the one that art represents objective reality, the one that it is representational, and the one that it is some kind of physical object) can be explicitly negated and effectively canceled. This is how new art movements were born out of the successful new definition. More importantly, there are always people who do not accept the definition that most people take to be definitional. This small but significant minority can constantly challenge, undermine, or plainly negate every one of the features that the majority takes to be definitional and essential. If they were essential, they could not be so easily challenged and canceled. We can suggest that the concept of art has a central member-the traditional conception-and many noncentral ones. The noncentral ones may become the prototypes of art for some people, and then these new prototypes can be further challenged. Concepts like art assume a prototype-based organization, and it is their very structure that invites contestation. We can only understand the nature of the widespread phenomenon of cultural and social debates if we study and understand the nature of our categories that give rise to and invite debates by virtue of their very structure. 
Our third example has to do with how we represent knowledge in the mind. Categories are mentally represented as frames, schemas, or models (see, e.g., Schank and Abelson 1977; Fillmore 1982; Langacker 1987; Lakoff 1987). We can use the following working definition of frames: A frame is a structured mental representation of a coherent organization of human experience.

Frames are important in the study of almost any facet of life and culture-and not just language. The world as we experience it is always the product of some prior categorization and framing by ourselves and others. A crucial aspect of framing is that different individuals can interpret the "same" reality in different ways. This is the idea of "alternative construal" mentioned above.

How do we categorize the various objects and events we encounter in the world? Clearly, many of our categories are based on similarity (especially of the family resemblance kind) among members of a category. That is, many categories are held together by family resemblances among the items that belong to a particular category. In this sense, most of our conventional categories for objects and events are similarity-based ones. For example, the things that one can buy in a store are commonly categorized based on their similarity to each other; thus, we find different kinds of nails (short and long ones, thick and thin ones, etc.) in the same section of a hardware store. They form a similarity-based category. However, we can also find nails in other sections of the store. Some nails can occur in sections where, for example, things for hanging pictures are displayed. Clearly, a nail is not similar to any of the possible things (such as picture frames, rings, short strings, adhesive tapes, maybe even a special hammer) displayed in this section. How is it possible that certain nails appear in this section? Or, to put it in our terms, how is it possible that nails are put in the same category with these other things? The answer is that in addition to similarity-based categories, we also have "frame-based" ones. That is to say, categories can be formed on the basis of which things go commonly and repeatedly together in our experience. If we put up pictures on the wall by first driving a nail into the wall and then hanging the picture frame on the nail by means of attaching a metal ring or a string on the frame, then all the things that we use for this purpose may be placed in a single category. But this category will be frame-based-not similarity-based. 
Now there can be differences across and even within cultures in the use of this meaning-making device. An interesting example is provided by a study by Glick (1975) conducted among the Kpelle of Liberia. Kpelle farmers consistently sorted objects into functional groups (such as knife and orange and potato and hoe), rather than into conceptual categories (such as orange and potato and knife and hoe). The former is what we would call frame-based categorization, whereas the latter is similarity-based one. On the whole, Westerners prefer to categorize objects based on similarity. When Glick asked the Kpelle how a fool would categorize the objects, they came up with such neat similarity-based piles. Clearly, cultures can differ in the use of meaning-making devices, and these differences may produce differences in the use of categories and language in general.

\section{UNIVERSAL METAPHORS}

Native speakers of all languages use a large number of metaphors when they communicate about the world (Lakoff and Johnson 1980). Such metaphorically used words and expressions may vary considerably across different languages. For example, the idea that English expresses with the words spending your time is expressed in Hungarian as filling your time. The "images" different languages and cultures employ can be extremely diverse. Given this diversity, it is natural to ask: Are there any universal metaphors at all, if by "universal" we mean those linguistic metaphors that occur in each and every language? Not only is this question difficult because it goes against our everyday experiences and intuitions as regards metaphorical language in diverse cultures, but also because it is extremely difficult to study, given that there are 4-6000 languages spoken around the world today.

However, if we go beyond looking at metaphorically used linguistic expressions in different languages, and, instead of linguistic metaphors, we look at conceptual metaphors, we begin to notice that many conceptual metaphors appear in a wide range of languages. For example, Hoyt Alverson (1994) found that the TIME IS SPACE conceptual metaphor can be found in such diverse languages and cultures as English, Mandarin Chinese, Hindi, and Sesotho. Many other researchers suggested that the same conceptual metaphor is present in a large number of additional languages. Several other conceptual metaphors appear in a large number of 
different languages. Kövecses (2000), based on evidence from a number of linguists who are native speakers of the respective languages, points out that English, Japanese, Chinese, Hungarian, Wolof, Zulu, Polish, and others, possess the metaphor AN ANGRY PERSON IS A PRESSURIZED CONTAINER to various degrees. Ning Yu's $(1995,1998)$ work indicates that the metaphor HAPPINESS IS UP is also present not only in English but also in Chinese. The system of metaphors called the Event Structure metaphor (Lakoff, 1993) includes submetaphors such as CAUSES ARE FORCES, STATES ARE CONTAINERS, PURPOSES ARE DESTINATIONS, ACTION IS MOTION, DIFFICULTIES ARE IMPEDIMENTS (то мотіоN), and so forth. Remarkably, this set of submetaphors occurs, in addition to English, in such widely different languages and cultures as Chinese (Yu 1998) and Hungarian (Kövecses 2005). Eve Sweetser (1990) noticed that THE KNOWING IS SEEING and the more general THE MIND IS THE BODY metaphors can be found in many European languages and are probably good candidates for (near-)universal metaphors. As a final example, Lakoff and Johnson (1999) describe the metaphors used for one's inner life in English. It turns out that metaphors such as SELF CONTROL IS OBJECT POSSESSION, SUBJECT AND SELF ARE ADVERSARIES, THE SELF IS A CHILD, are shared by English, Japanese, and Hungarian. Given that one's inner life is a highly elusive phenomenon, and hence would seem to be heavily culture- and language-dependent, one would expect a great deal of significant cultural variation in such a metaphor. All in all, then, we have a number of cases that constitute near-universal or potentially universal conceptual metaphors, although not universal metaphors in the strong sense.

How Can We Have (near-)Universal Metaphors?

How is it possible that such conceptual metaphors exist in such diverse languages and cultures? After all, the languages belong to very different language families and represent very different cultures of the world. Several answers to this question lend themselves for consideration. First, we can suggest that by some miracle all these languages developed the same conceptual metaphors for happiness, time, purpose, etc. Second, we can consider the possibility that languages borrowed the metaphors from each other. Third, we can argue that there may be some universal basis for the same metaphors to develop in the diverse languages.

Let us take as an example the HAPPINESS IS UP conceptual metaphor, first discussed by Lakoff and Johnson (1980) in English. The conceptual 
metaphor can be seen in such linguistic expressions as to feel up, to be on cloud nine, to be high, and others. Yu (1995, 1998) noticed that the conceptual metaphor can also be found in Chinese. And evidence shows that it also exists in Hungarian. Below are some linguistic examples: (Yu used the grammatical abbreviations $\mathrm{PRT}=$ particle and ASP $=$ aspect marker.)

Chinese:

HAPPY IS UP

Ta hen gao-xing.

he very high-spirit

He is very high-spirited/happy.

Ta xing congcong de.

he spirit rise-rise PRT

His spirits are rising and rising./He's pleased and excited.

Zhe-xia tiqi le wo-de xingzhi.

this-moment raise ASP my mood

This time it lifted my mood/interest.

Hungarian:

HAPPINESS IS UP

Ez a film feldobott.

this the film up-threw-me

This film gave me a high.-This film made me happy.

Majd elszáll a boldogságtól.

almost away-flies-he/she the happiness-from

$\mathrm{He} / \mathrm{she}$ is on cloud nine.

English, Mandarin Chinese, and Hungarian (a Finno-Ugric language) belong to different language families, which developed independently for much of their history. It is also unlikely that the three languages had any significant impact on each other in their recent history. This is not to say that such an impact never shapes particular languages as regards their metaphors (e.g., the processes of globalization and the widespread use of the internet may "popularize" certain conceptual metaphors, such as TIME 
IS A COMMODITY), but only to suggest that the particular HAPPINESS IS UP metaphor does not exist in the three languages because, say, Hungarian borrowed it from Chinese and English from Hungarian.

So how did the same conceptual metaphor emerge then in these diverse languages? The best answer seems to be that there is some "universal bodily experience" that led to its emergence. Lakoff and Johnson argued early that English has the metaphor because when we are happy, we tend to be physically up, moving around, be active, jump up and down, smile (i.e., turn up the corners of the mouth), rather than down, inactive, and static, and so forth. These are undoubtedly universal experiences associated with happiness (or more precisely, joy), and they are likely to produce potentially universal (or near-universal) conceptual metaphors. The emergence of a potentially universal conceptual metaphor does not, of course mean that the linguistic expressions themselves will be the same in different languages that possess a particular conceptual metaphor (Barcelona 2000; Maalej 2004).

Kövecses $(1990,2000)$ proposed, furthermore, that the universal bodily experiences can be captured in the conceptual metonymies associated with particular concepts. Specifically, in the case of emotion concepts, such as happiness, anger, love, pride, and so forth, the metonymies correspond to various kinds of physiological, behavioral, and expressive reactions. These reactions provide us with a profile of the bodily basis of emotion concepts. Thus, the metonymies give us a sense of the embodied nature of concepts, and the embodiment of concepts may be overlapping, that is, (near-)universal, across different languages and language families. Such universal embodiment may lead to the emergence of shared conceptual metaphors.

Joseph Grady (1997) developed the Lakoff-Johnson view further by proposing that we need to distinguish "complex metaphors" from "primary metaphors." His idea was that complex metaphors (e.g., THEORIES ARE BUILDINGS) are composed of primary metaphors (e.g., LOGICAL ORGANIZATION IS PHYSICAL STRUCTURE). The primary metaphors consist of correlations of a subjective experience with a physical experience. As a matter of fact, it turned out that many of the conceptual metaphors discussed in the cognitive linguistic literature are primary metaphors in this sense. For instance, HAPPY IS UP is best viewed as a primary metaphor, where being happy is 
a subjective experience and being physically up is a physical one that is repeatedly associated with it. Other primary metaphors include MORE Is UP, PURPOSES ARE DESTINATIONS, and INTIMACY IS CLOSENESS. On this view, it is the primary metaphors that are potentially universal.

Primary metaphors function at a fairly local and specific level of conceptualization, and hence in the brain. At the same time, the brain is also characterized by much more global metaphoric potentialities, or principles. Indeed, the major research question for several cognitive archeologists is: What kind of brain is necessary for metaphorical thought? Cognitive archeologist Steven Mithen $(1996,1998)$ suggests that the brain of humans before the Upper Paleolithic period in Europe (100,000 to 30,000 years ago) was a domain specific brain. In it, cognitive domains related to tools, the natural world, and social interaction were isolated. These early humans were not capable of metaphoric thought until the Upper Paleolithic period, when the domain-specific brain became more fluid and allowed the interpretation of knowledge in one domain in terms of knowledge in another domain. This newer brain was a "cognitively fluid" brain. For example, in cave drawings people may be represented as animals. In the terminology of the cognitive linguistic view of metaphor, humans in the Upper Paleolithic developed the PEOPLE ARE ANIMALS conceptual metaphor. Other conceptual metaphors pointed out by Mithen (1998: 171) include:

ANIMALS AND PLANTS ARE PEOPLE

ANIMALS AND PLANTS ARE STRUCTURED OBJECTS

PEOPLE ARE STRUCTURED OBJECTS

Furthermore, in the same way as animals can be metaphorically viewed as humans and humans can be viewed as animals, objects can be seen as humans. A famous example of this was described by Keith Basso (1967), who showed that in the language of the Western Apache cars are metaphorically viewed in terms of the human body. In addition, Bernd Heine and his colleagues work (Heine, Hünemeyer, \& Claudi 1991, Heine 1995, Heine \& Kuteva 2002) reveals other large-scale metaphorical processes people seem to employ (near-)universally; for example, spatial relations are commonly understood as parts of the human body (e.g., the head means up and the feet means down). These conceptual metaphors and the largescale processes they underlie are global design-features of the brain/mind 
of modern humans. They represent global metaphoric potentialities, or principles, of a cognitively fluid brain.

It seems to be clear at this point that commonality in human experience is a major force shaping the metaphors we have. It is this force that gives us many of the metaphors that we can take to be near-universal or potentially universal. But commonality in human experience is not the only force that plays a role in the process of establishing and using metaphors. There are also counterveiling forces that work against universality in metaphor production.

\section{CAUses OF METAPHOR VARIATION}

Heine's work also shows that not even such global metaphors as SPATIAL RELATIONS ARE PARTS OF THE BODY are universal in an absolute sense. There are languages in which spatial relations are conceptualized not as the human but as the animal body. He points out that such languages function in societies where animal husbandry is a main form of subsistence. This leads us to the question: What causes our metaphors to vary as they do? It is convenient to set up two large groups of causes: differential experience and differential cognitive preferences. Differential experience involves differences in social-cultural context, in social and personal history, and in what we can term social and personal concern or interest (see Kövecses 2005).

One example of how the social-cultural context can shape conceptual metaphors is provided by Geeraerts and Grondelaers (1995). They note that in the Euro-American tradition it is the classical-medieval notion of the "four humors" from which the Euro-American conceptualization of anger (as well as that of emotion in general) derived. The humoral view maintains that the four fluids (phlegm, black bile, yellow bile, and blood) and the temperatures associated with them regulate the vital processes of the human body. They were also believed to determine personality types (such as sanguine, melancholy, etc.) and account for a number of medical problems. The humoral view exerted a major impact on the emergence of the European conception of anger as a hot fluid in a pressurized container. By contrast, King (1989) and Yu (1995 and 1998) suggest that the Chinese concept of "nu" (corresponding to anger) is bound up with the notion of "qi," that is, the energy that flows through the body. "Qi" in 
turn is embedded in not only the psychological (i.e., emotional) but also the philosophical and medical discourse of Chinese culture and civilization. When "qi" rises in the body, there is anger ("nu"). Without the concept of "qi," it would be difficult to imagine the view of anger in Chinese culture. Thus emotion concepts, such as anger in English, "düh" in Hungarian (the two representing European culture), and "nu" in Chinese, are in part explained in the respective cultures by the culture-specific concepts of the four humors and "qi," respectively. It appears that the culture-specific key concepts that operate in particular cultures account for many of the specific-level differences among the various anger-related concepts and the PRESSURIZED CONTAINER metaphor.

Differences in the metaphors we have in particular cultures may also derive from social and personal history. As work by Köves reported in Kövecses (2005) shows, Hungarians primarily use the LIFE IS WAR and LIFE IS A COMPROMISE metaphors for comprehending the concept of life in general, whereas Americans predominantly employ the LIFE IS A PRECIOUS POSSESSION and LIFE IS A GAME metaphors. Why do Hungarians use the metaphors they do for life, and why do Americans use different ones? The issue obviously has to do with the peculiarities of Hungarian and American history. Hungarians have been in wars throughout their more than one thousand year old history as a nation and state and had to struggle for their survival as they are wedged between powerful German-speaking and Slavic nations. Given this history, it is not surprising that for many Hungarians life is struggle-and less of a game. To point this out is, of course, trivial as far as history is concerned, but it is not trivial as far as the study of the emergence of a particular metaphorical conceptual system is concerned.

Finally, for an example of how differences in human concern can create new metaphors, consider some well known conceptual metaphors for sadness: SADNESS IS DOWN, SADNESS IS A BURDEN, and SADNESS IS DARK. The counterpart of sadness is depression in a clinical context. Linda McMullen and John Conway (2002) studied the metaphors that people with episodes of depression use and, with one exception, found the same conceptual metaphors for depression that "non-depressed" people use for sadness. They identified the unique metaphor as DEPRESSION IS A CAPTOR. Why don't "merely" sad people talk about sadness as being a "captor"? Most people do not normally talk about being trapped by, wanting to be free of, or wanting to break out of sadness, although these are ways of talking and thinking 
about depression in a clinical context. It makes sense to suggest that people with depression use this language and way of thinking about their situation because it faithfully captures what they experience and feel. Their deep concern is with their unique experiences and feelings that set them apart from people who do not have them. It is this concern that gives them the "captor" metaphor for depression.

People can employ a variety of different cognitive operations in their effort to make sense of experience. For example, what I call "experiential focus" can have an impact on the specific details of the conceptual metaphors used and what is conceptualized metaphorically in one culture can predominantly be conceptualized by means of metonymy in another.

Let us begin with experiential focus (Kövecses 2005). The universal bodily basis on which universal metaphors could be built may not be utilized in the same way or to the same extent in different languages. What experiential focus means is that different peoples may be attuned to different aspects of their bodily functioning in relation to a metaphorical target domain, or that they can ignore or downplay certain aspects of their bodily functioning with respect to the metaphorical conceptualization of a target domain. A case in point is the conceptualization of anger in English and Chinese. As studies of the physiology of anger across several unrelated cultures show, increase in skin temperature and blood pressure are universal physiological correlates of anger (Levenson et al, 1992). This accounts for the ANGER IS HEAT metaphor in English and in many other languages. However, King's and Yu's work mentioned above suggest that the conceptualization of anger in terms of heat is much less prevalent in Chinese than it is in English. In Chinese, the major metaphors of anger seem to be based on pressure-not heat. This indicates that speakers of Chinese have relied on a different aspect of their physiology in the metaphorical conceptualization of anger than speakers of English. The major point is that in many cases the universality of experiential basis does not necessarily lead to universally equivalent conceptualization-at least not at the specific level of hot fluids.

Are there any differences in the way the cognitive processes of metaphor versus metonymy are used in different languages and cultures? Jonathan Charteris-Black examined in great detail how and for what purpose three concepts-mouth, tongue, and lip-are figuratively utilized in English and 
Malay. He found similarities in metaphorical conceptualization. For example, in both languages, the same underlying conceptual metaphor (e.g., MANNER IS TASTE) accounts for expressions like honey-tongued and lidah manis ('tongue sweet') and in both languages such expressions are used for the discourse function of evaluating (especially negatively) what a person says. However, he also found that the figurative expressions involving the three concepts tended to be metonymic in English and metaphoric in Malay. In English, more than half of the expressions were metonyms, while in Malay the vast majority of them showed evidence of metaphor (often in combination with metonymy). For example, while metonymic expressions like tightlipped abound in English, such expressions are much less frequent in Malay. It seems that, at least in the domain of speech organs, the employment of these concepts by means of figurative processes is culture-specific.

\section{Conclusions}

Culture and language are connected in many ways and the interconnections can be studied from a variety of different perspectives. Following Clifford Geertz, I tried to develop a view of the relationship that is based on how we make sense of our experiences-linguistic or otherwise. Recent cognitive science and cognitive linguistics provide us with new ideas and methodological tools with which we can approach the issue of meaningmaking in cultures both in its universal aspects and in its infinite crosscultural variety.

Metaphorical linguistic expression may vary widely cross-culturally but many conceptual metaphors appear to be potentially universal or near-universal. This happens because people across the world share certain bodily experiences. However, even such potentially universal metaphors may display variation in their specific details because people do not use their cognitive capacities in the same way from culture to culture. Finally, many conceptual metaphors are unique to particular cultures or sets of cultures because of differences in such factors as social-cultural context, history, or human concern that characterize these cultures.

Recebido em junho de 2009

Aprovado em abril de 2010

E-mail: zkovecses@ludens.elte.hu 


\section{REFERENCES}

Alverson, Hoyt. 1991. Metaphor and experience: Looking over the notion of image schema. In J. Fernandez, ed., Beyond Metaphor: The Theory of Tropes in Antbropology. 94-117. Stanford: Stanford University Press. . 1994. Semantics and Experience: Universal Metaphors of time in English, Mandarin, Hindi, and Sesotho. Baltimore: Johns Hopkins University Press.

Barcelona, Antonio. 2000. On the plausibility of claiming a metonymic motivation for conceptual metaphor. In A. BARCELONA (Ed.) Metaphor and Metonymy at the Crossroads. Berlin: Mouton de Gruyter.

Basso, Keith H. 1967. Semantic Aspects of Linguistic Acculturation. American Antbropologist, New Series, 69/5: 471-477.

Charteris-Black, Jonathan. 2003. Speaking with forked tongue: A comparative study of metaphor and metonymy in English and Malay phraseology. Metaphor and Symbol, 18/4: 289-310.

. 2004. Corpus Approaches to Critical Metaphor Analysis. Palgrave Macmillan.

Encyclopedia Britannica Ready Reference. 2003. Version on Dell computers.

Fillmore, Charles. 1982. Frame semantics. Linguistics in the Morning Calm, 111-137. The Linguistic Society of Korea. Hanshin.

Geeraerts, Dirk and Stephan Grondelaers. 1995. Looking back at anger: cultural traditions and metaphorical patterns. In J. TAYLOR and R. MACLAURY (eds.) Language and the cognitive construal of the world. Berlin: Gruyter.

Geertz, Clifford. 1973. The Interpretation of Cultures. New York: Basic Books.

GLICK, J. 1975. Cognitive development in cross-cultural perspective. In F. Horowitz (Ed.) Review of child development research: Vol. 4. Chicago: University of Chicago Press.

Goatly, Andrew. 2007. Washing the Brain. Metaphor and Hidden Ideology. Amsterdam: John Benjamins.

Grady, Joseph. 1997. Foundations of Meaning: Primary Metaphors and Primary Scenes. Ph.D. diss. Department of Linguistics, University of California at Berkeley.

HeIne, Bernd. 1995. Conceptual grammaticalization and prediction. In J. TAYlor and R. MAcLaury (eds.) Language and the Cognitive Construal of the World. 119-135. Berlin: Mouton de Gruyter. 
\& Kuteva, Tania. 2002. World Lexicon of Grammaticalization.

Cambridge: Cambridge University Press.

, Claudi, Ulrike \& HüNEMEYER, Friederike. 1991. Grammaticalization:

A Conceptual Framework. Cambridge: Cambridge University Press.

Johnson, Mark. 1987. The Body in the Mind. Chicago: The University of Chicago Press.

Kimmel, Michael. 2001. Metaphor, Imagery, and Culture. Spatialized

Ontologies, Mental Tools, and Multimedia in the Making. Unpublished Ph.D. dissertation. University of Vienna.

KING, Brian. 1989. The conceptual structure of emotional experience in Chinese.

Ph.D. dissertation. Ohio State University.

Kövecses, Zoltán. 1990. Emotion Concepts. Berlin and New York: SpringerVerlag.

. 2000. Metaphor and Emotion. New York and Cambridge:

Cambridge University Press. .2005. Metaphor in Culture. Universality and Variation. Cambridge

and New York: Cambridge University Press. .2006. Language, Mind, and Culture. A Practical Introduction. Oxford and New York: Oxford University Press.

KramsCh, Claire. 1998. Language and Culture. Oxford: Oxford University Press.

Lakoff, George. 1987. Women, Fire, and Dangerous Thing. Chicago:The University of Chicago Press. . 1993. The contemporary theory of metaphor. In A. ORTONY (Ed.) Metaphor and Thought, 202-251. Cambridge: Cambridge University Press.

1996. Moral Politics. How Liberals and Conservatives Think. Chicago: The University of Chicago Press.

Lakoff, George and Johnson, Mark. 1980. Metaphors We Live By. Chicago:

The University of Chicago Press. .1999. Philosophy in the Flesh. New York: Basic Books.

LANGACKer, Ronald. 1987. Foundations of Cognitive Grammar. Theoretical Prerequisites. 1. Stanford: Stanford University Press.

Levenson, R. W., P. Ekman, K. Heider, and W. V. Friesen. 1992. Emotion and autonomic nervous system activity in the Minangkabau of West Sumatra. Journal of Personality and Social Psychology. 62: 972-988.

Levinson, Stephen C. 1996. Relativity in spatial conception and description. In J. Gumperz and S. C. Levinson (eds.) Rethinking Linguistic Relativity. Cambridge: Cambridge University Press. 
MAALEJ, Zouhair. 2004. Figurative language in anger expressions in Tunisian Arabic: An extended view of embodiment. Metaphor and Symbol, 19/1: 51-75.

McMullen, Linda and John Conway. 2002. Conventional metaphors for depression. In S. Fussell (ed.) Verbal communication of emotion: interdisciplinary perspectives. 167-181. Mahwah: Lawrence Erlbaum.

Mithen, Steven. 1996. The Prehistory of the Mind: A Search for the Origin of Art, Science and Religion. London and New York: Thames and Hudson.

Mithen, Steven. 1998. A creative explosion? Theory of mind, language, and the disembodied mind of the Upper Paleolithic. In S. Mithen (ed.) Creativity in Human Evolution and Prehistory, 165-191. London and New York: Routledge.

Musolff, Andreas. 2004. Metaphor and political discourse. Analogical reasoning in debates about Europe. London: Palgrave Macmillan.

Palmer, Gary. 1996. Toward a Theory of Cultural Linguistics. Austin: Texas University Press.

Schank, Robert and Robert Abelson. 1977. Scripts, Plans, Goals, and Understanding. Hillsdale, N.J.: Lawrence Erlbaum.

Sweetser, Eve. 1990. From Etymology to Semantics. Cambridge/New York: Cambridge University Press.

Turner, Mark. 2001. Cognitive Dimensions of Social Science. Oxford and New York: Oxford University Press.

YU, Ning. 1995. Metaphorical expressions of anger and happiness in English and Chinese. Metaphor and Symbolic Activity, 10: 59-92.

Yu, Ning. 1998. The contemporary theory of metaphor in Chinese: A perspective from Chinese. Amsterdam: John Benjamins. 